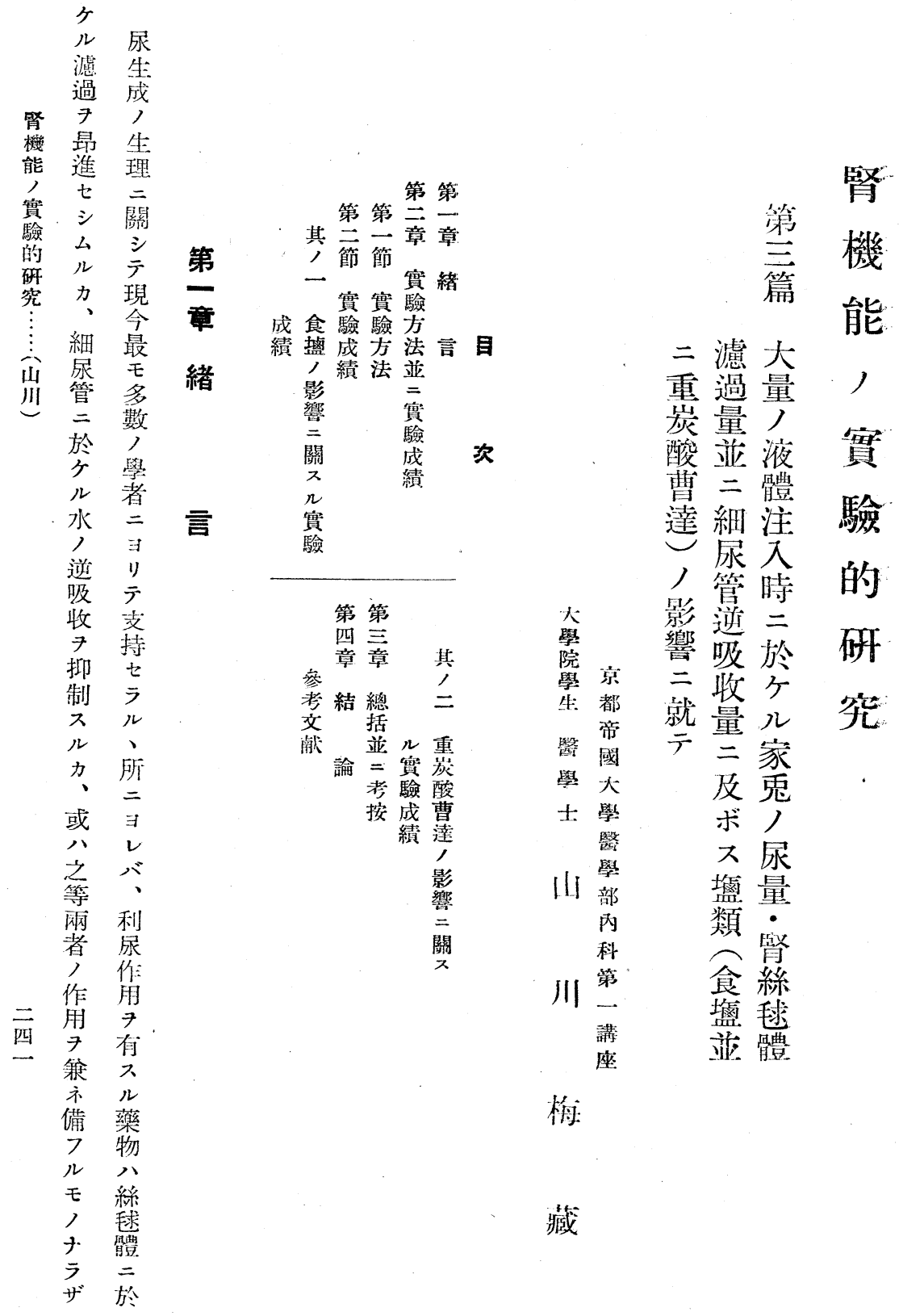




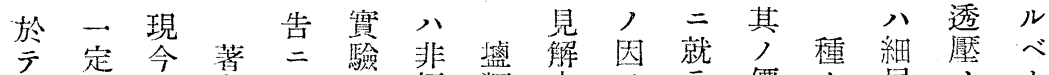

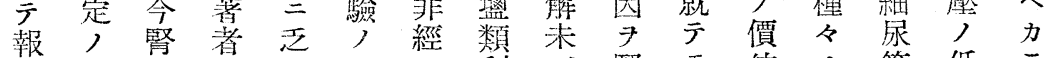

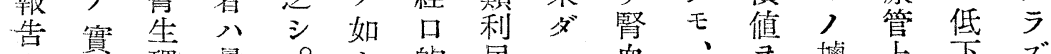

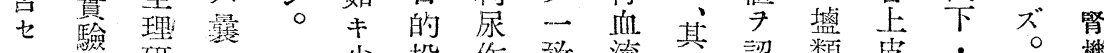

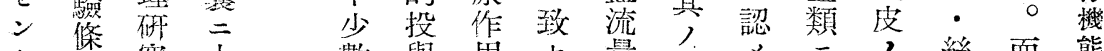
卜件究大數與用七量他 $x=>$ 絲而能

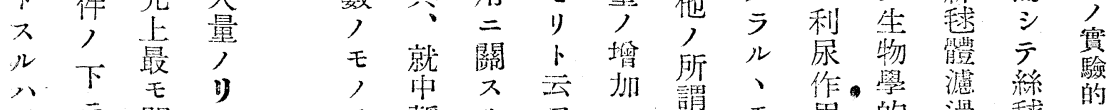

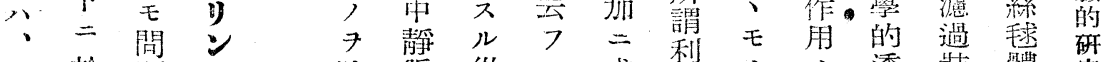
大於題皇 量

り 斯 $v$ 液

ンル 居 注

更影先入

ル 響 多,

氐 7 糖 尿

液除類 量

注外页它

二得り綵

ヨルン 㲑

ルコ, 僼

尿卜利滤

量 7 尿過

鮆證抑量

加明制 並

辕 三 作 二

二、用細

於 其 二 尿

テ, 就 管

“結 厂 逆

丞相記收

量 7 述 量

篮 第 三

絲篇人ボ

㤹 尔 邓

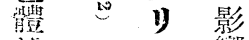

濾二ン 響

過於八二

量 亏 利 就

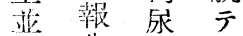

二告 抑檢

細七扯索

尿少作 シ

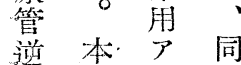

逆 本 ア 同
篇 $ル$ 時

收 $=$ $=$

、射賽得卜作卜丿人透量 山1

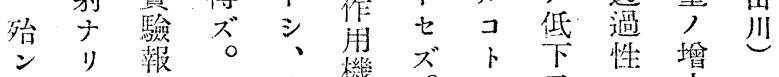

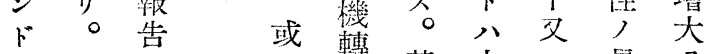
ス而 7 少其古八昂 7

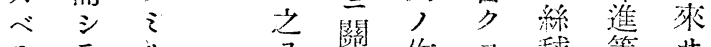
テ テ ル

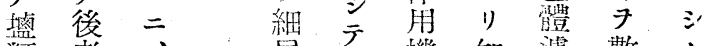
類者、求種機 知滤數么 $\exists$ 㙉、管草轉 ラ 液 7 ル

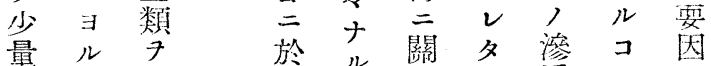

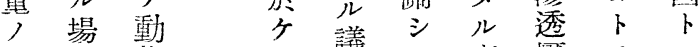

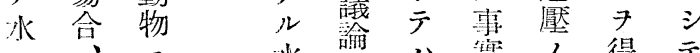

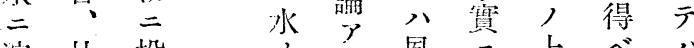

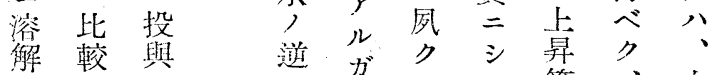

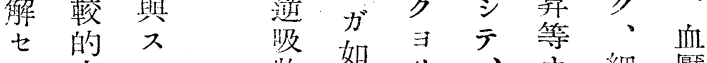
シ大ル 收如り、ナ細 壓 ×量二八刀、多盐引引展了

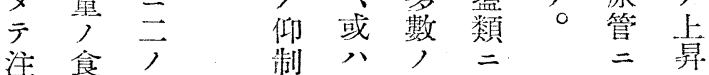
注食方制 水蓝 水法 ヨ血績テ多綵

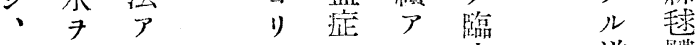
大注り ラ二リ床

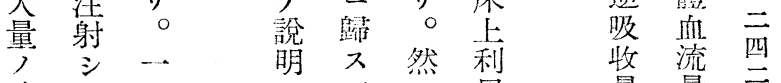

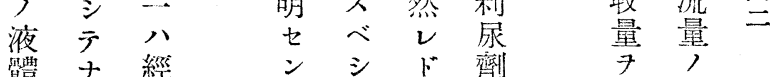

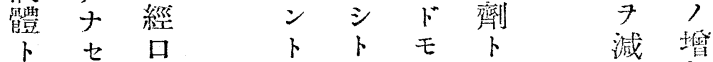
共ル的主盐 $三$ 少 扣

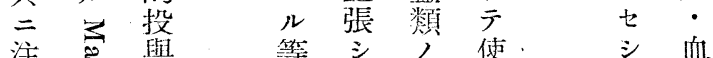

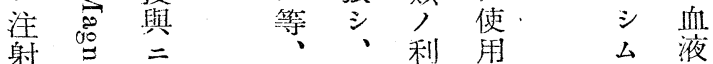

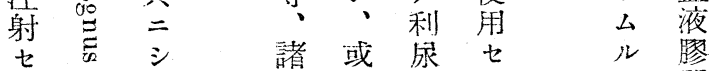
ル 家少作 ラ 䇉, 他其角レ淩 


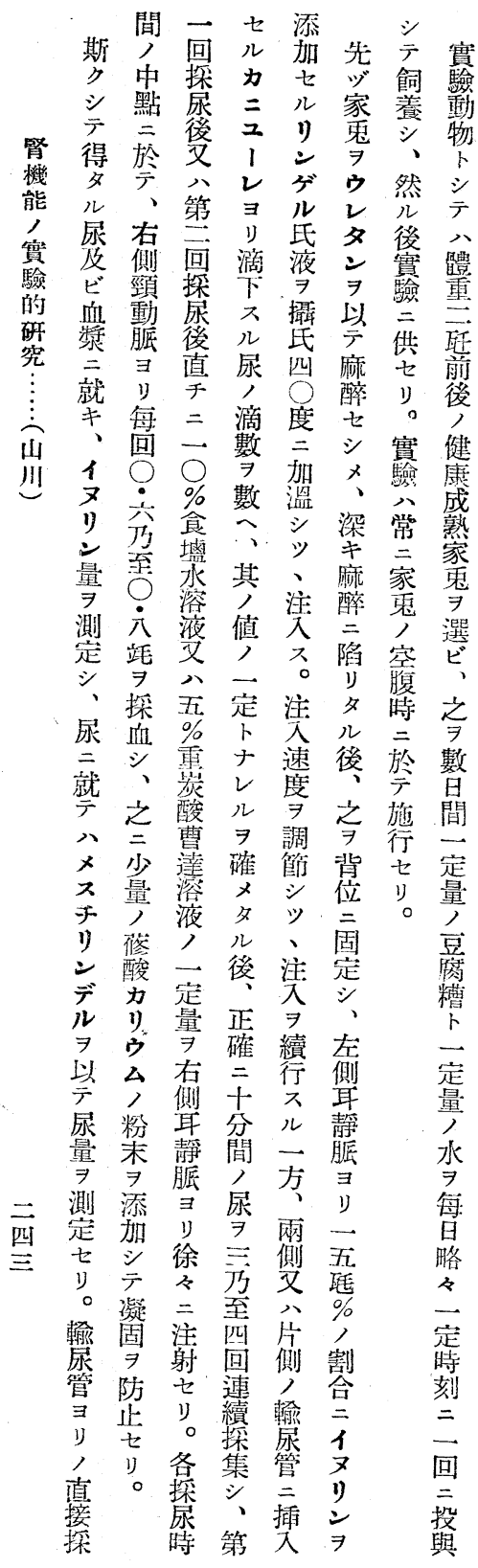

ン八二闪廌量

ト. 㭧 興 $=7=$

, 害 味 於却於及

想ナアケ制 ケ ボ

定ルルルシルス

ヨココ 濾テ水 墭

リト卜過浮分類

出、ナ・腄, 分

デ、リ逆ノ移影

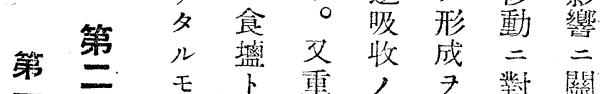

節聕, モ

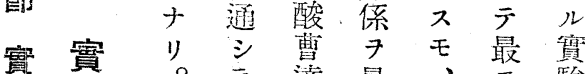

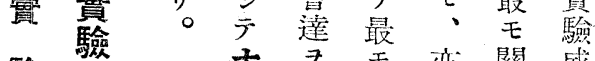

ナ $モ$ 亦闒成

驗方使正其係續

方法品用礁少深二

ウ七二血秚 シ

法三出儿示中比

1 $、$ 濃,

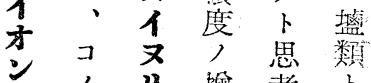

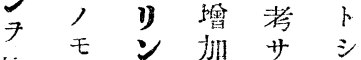

抱, 法八礼

含 小二時屈食

ス生目二ル 堖

ル理り利電道

點的 テ 尿 解 二

丮二食現賢重

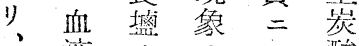

液,

计堅原テ、曹

存能卜其

作 在二七, 選

用 ス 数 ラ投

$\begin{array}{lllll}\text { 分物 } & \text { ル } & \text { 與 } & \text { デ } \\ \text { 使 }\end{array}$

析質影浮、用

ス 二響无原 七

ルシ 当ナ準り

二テ、分利、䚚。

用從 $x$ w態

得テ八即於食

ル生 $、$ テ 少

ナ蒀コ腎 八生

ラ二ト藏利 需击 


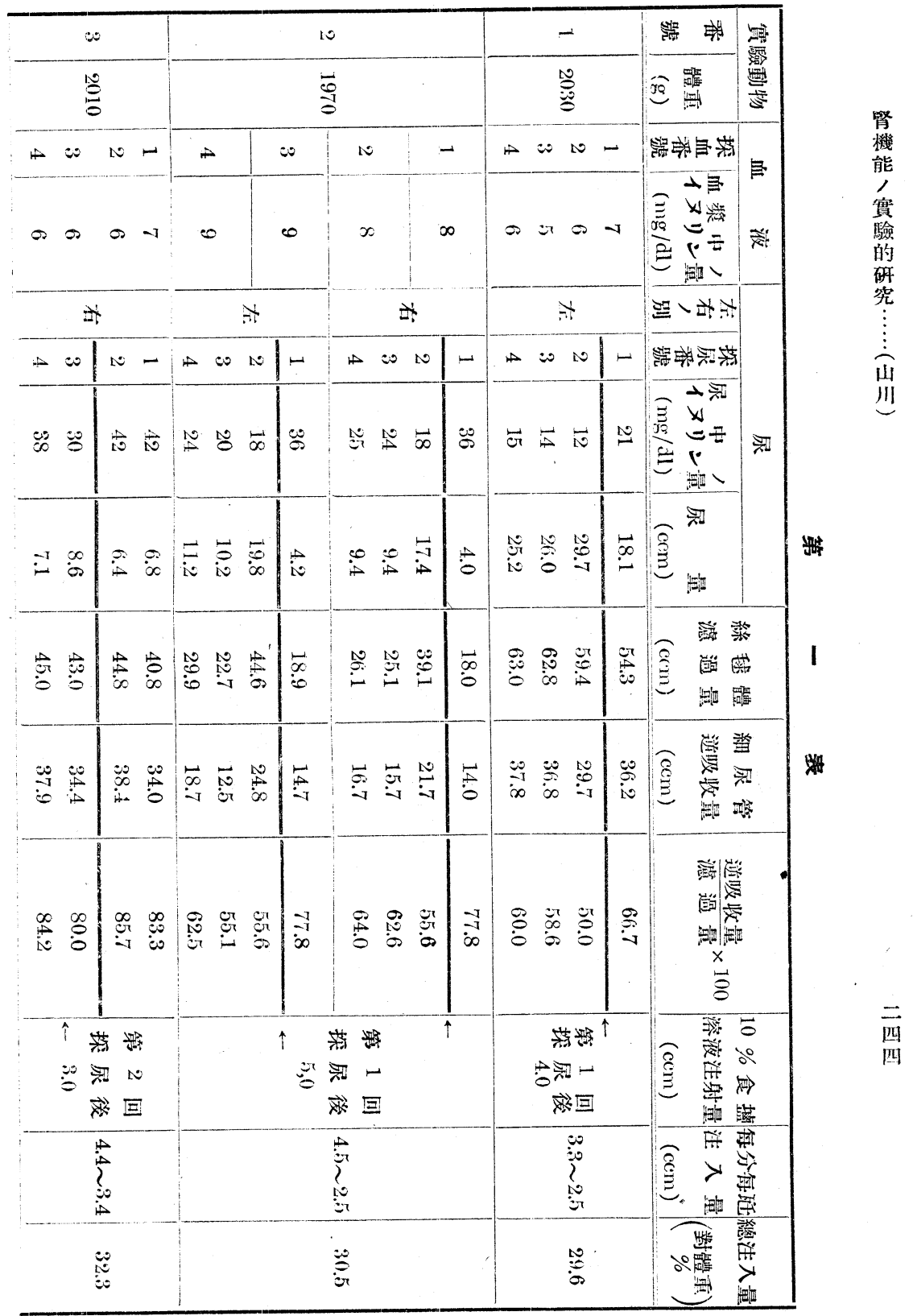




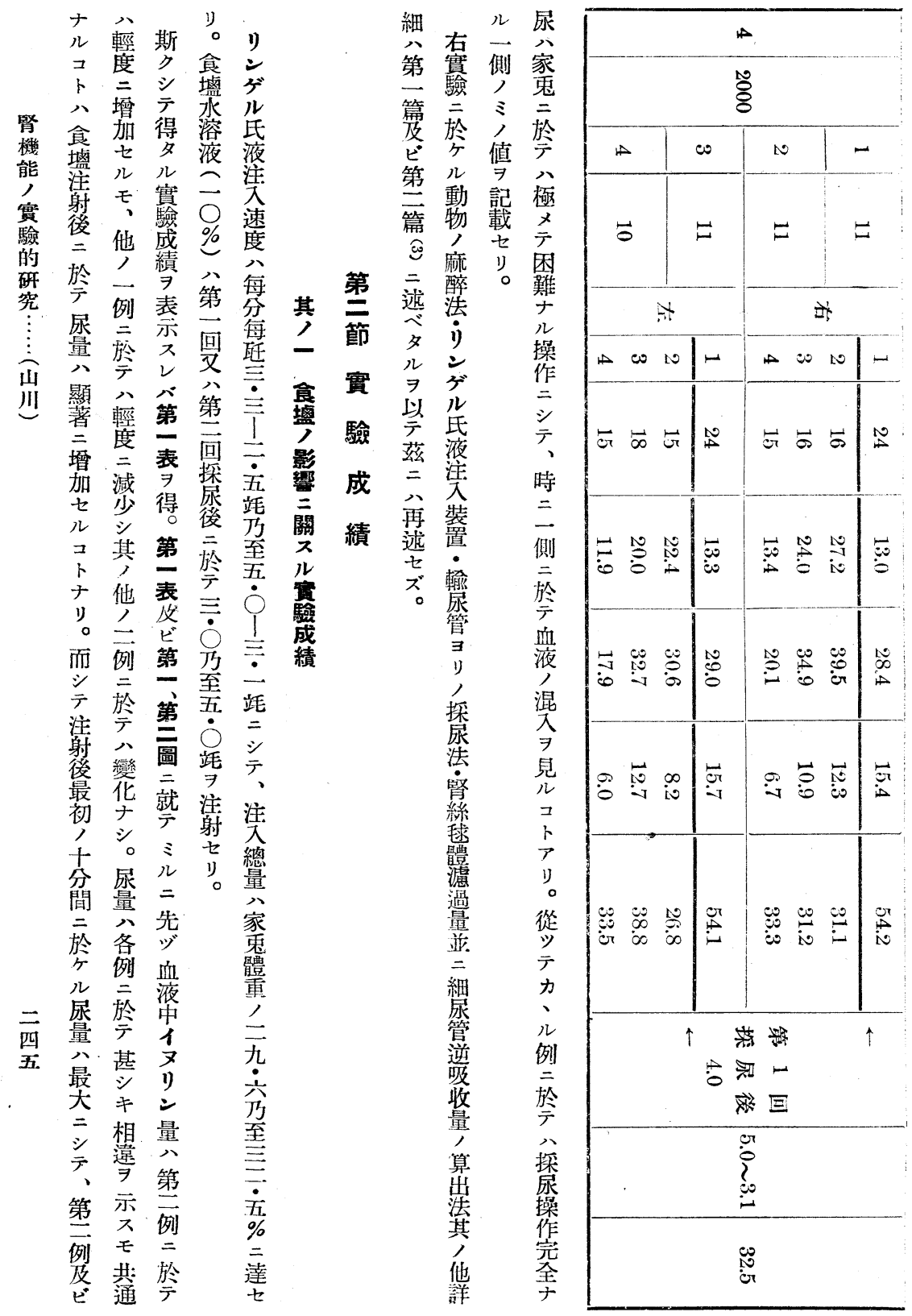




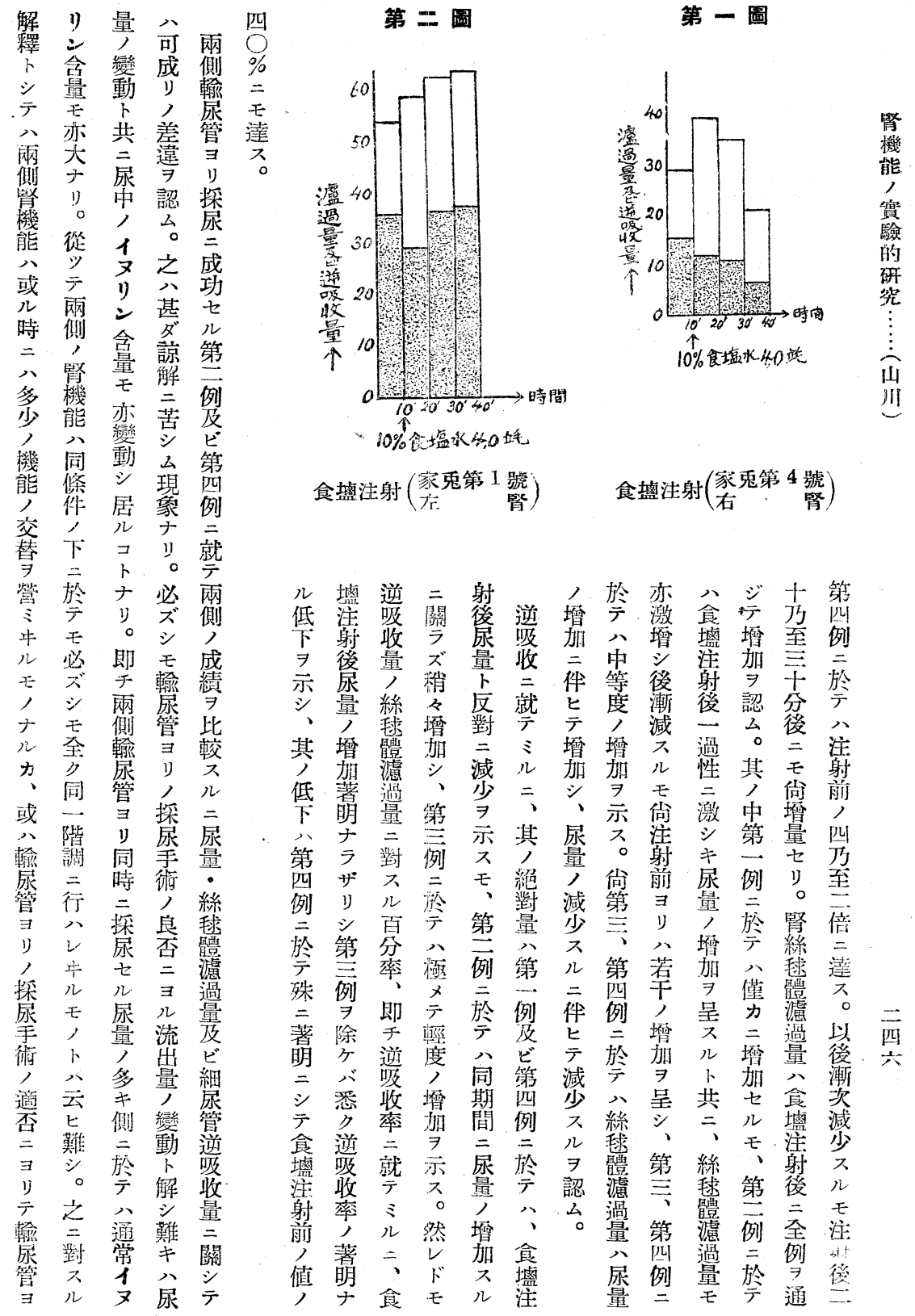




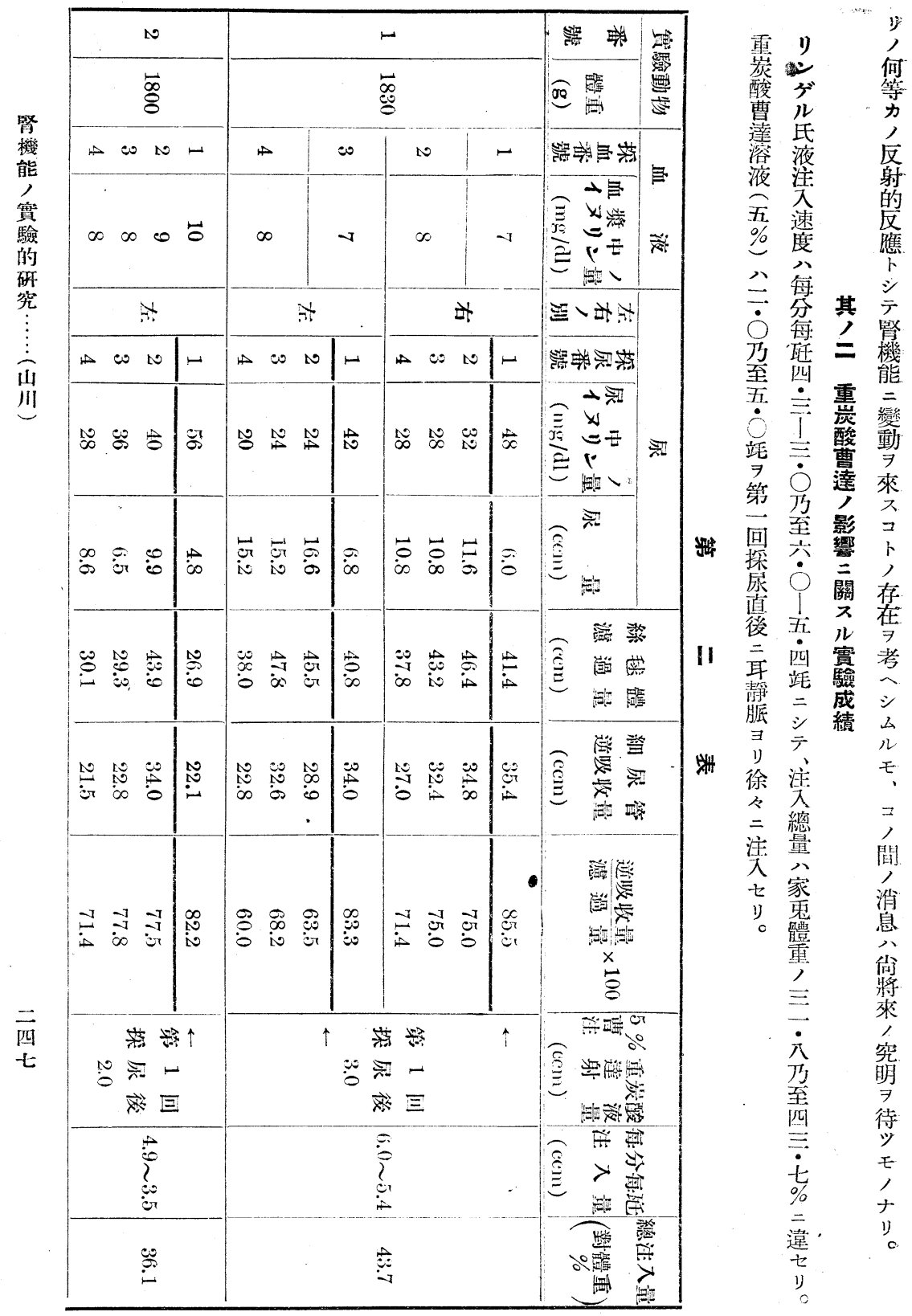




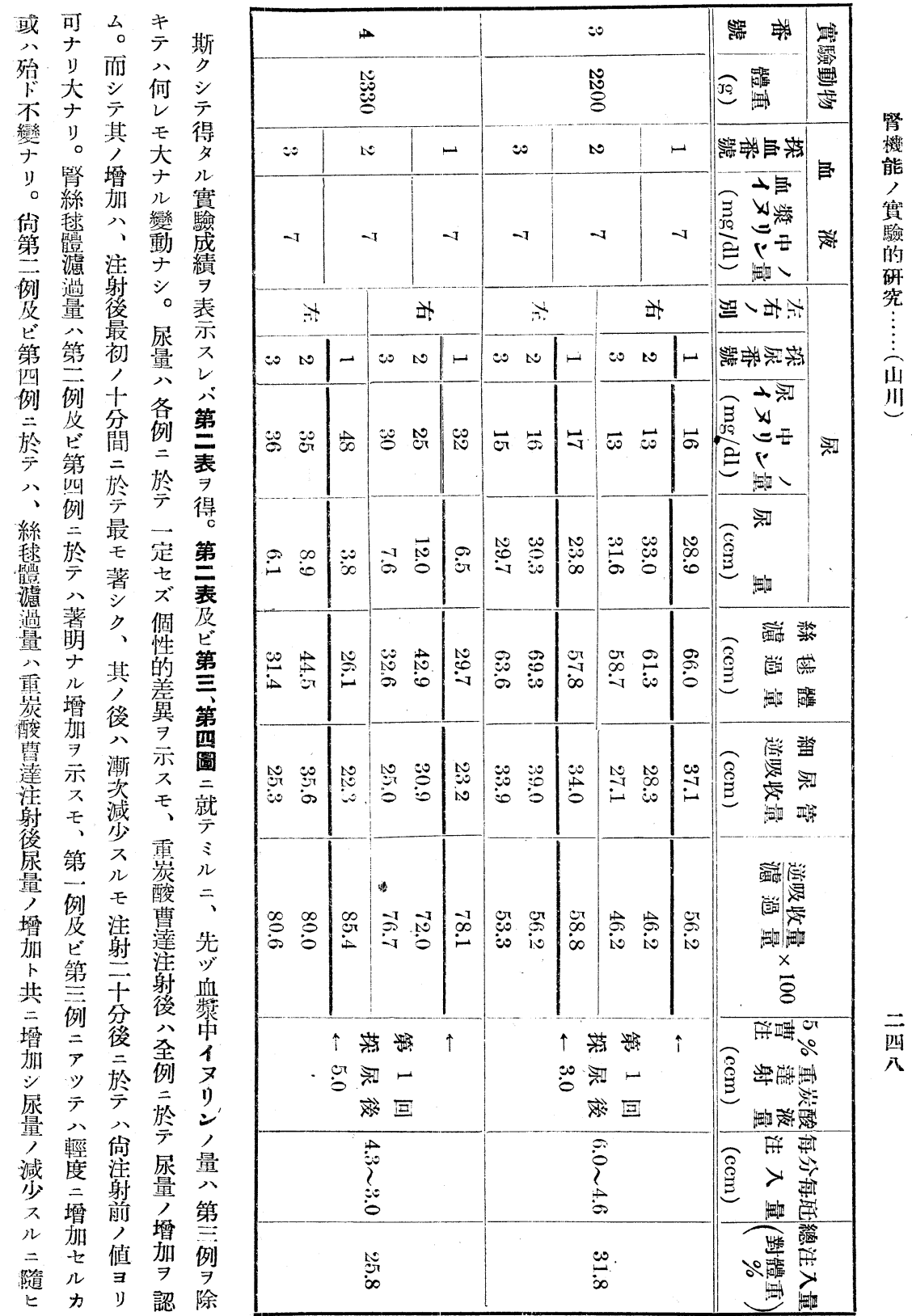




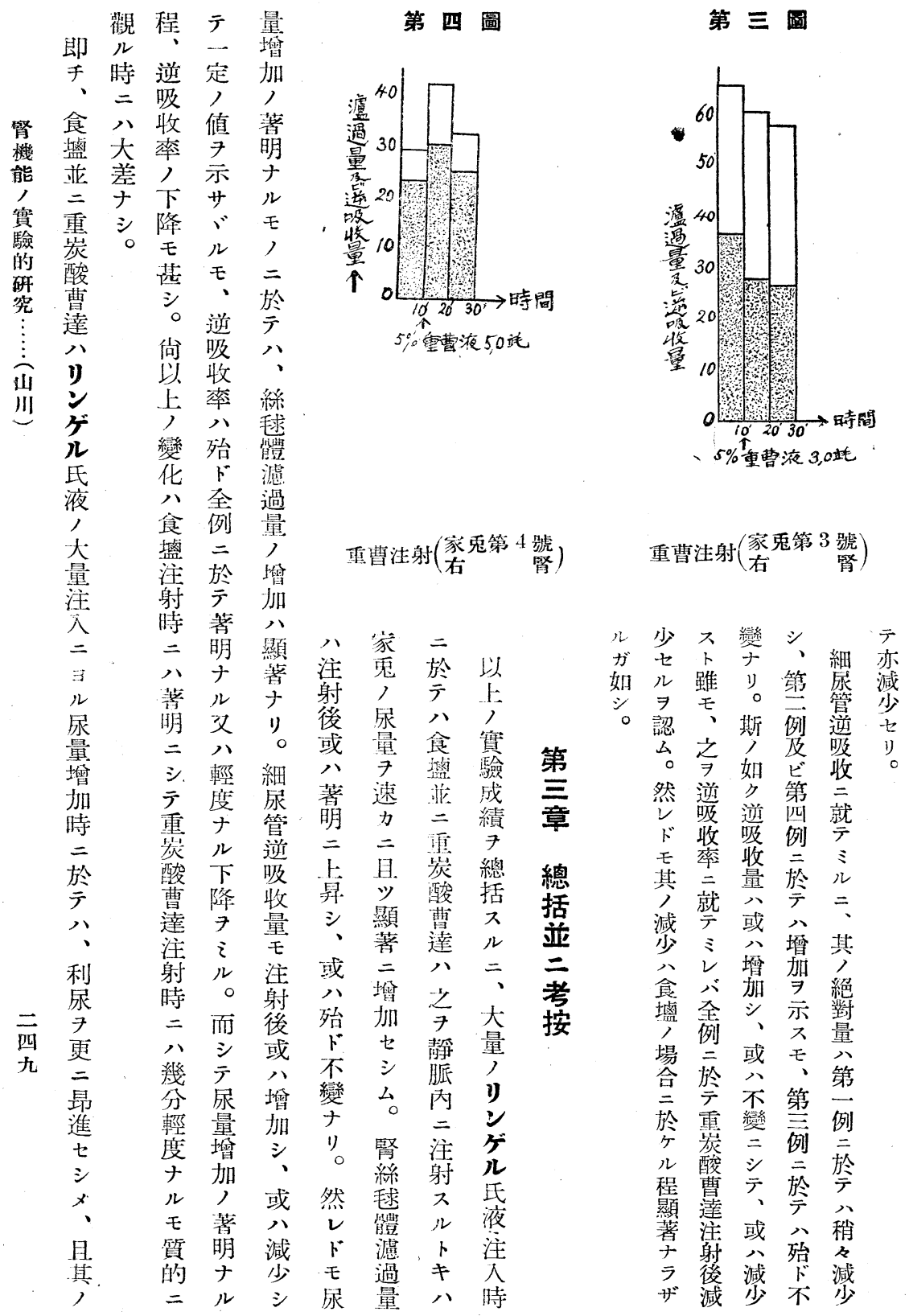




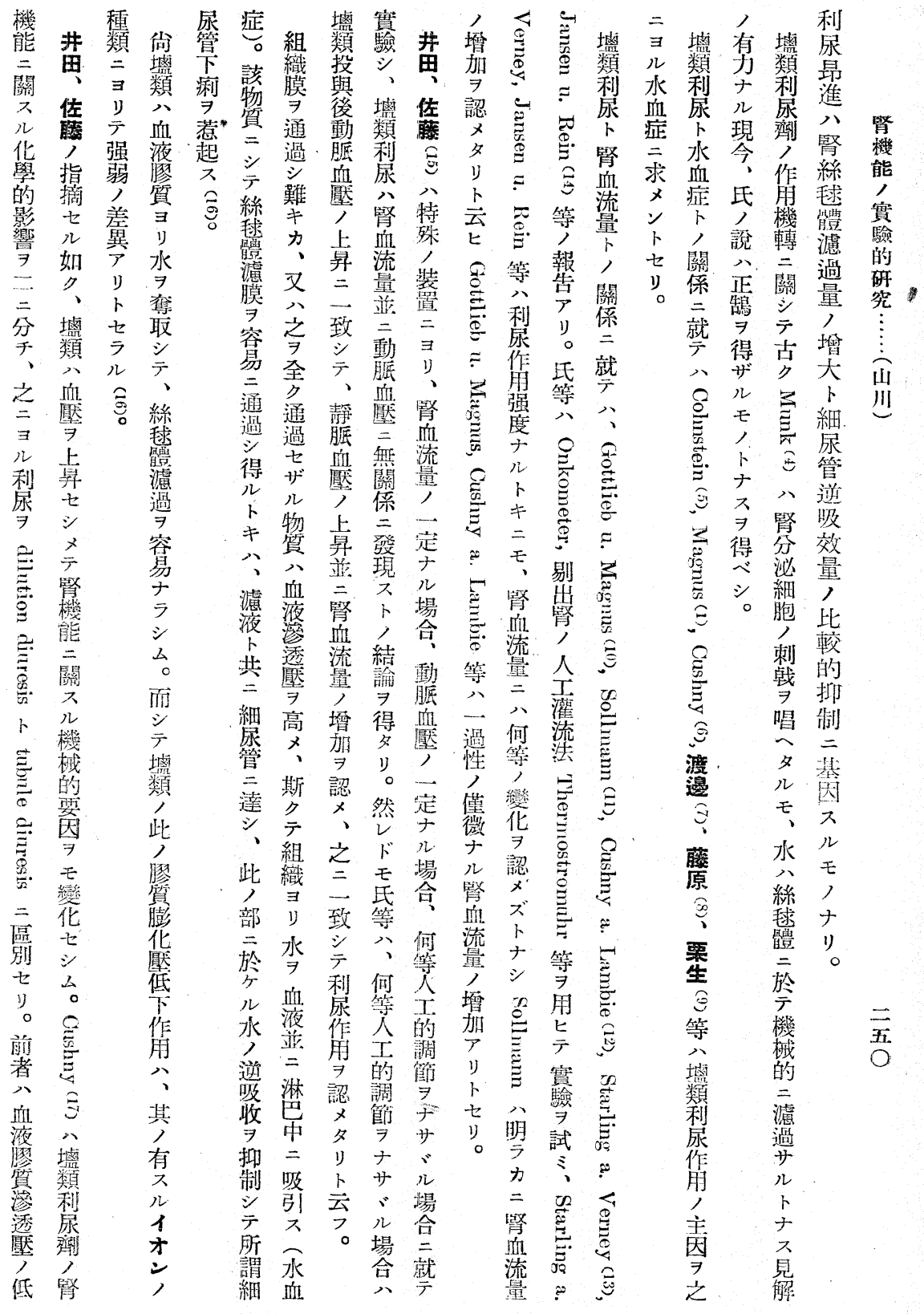


解 利フ考 ゲ ス ゲ ガ 注 制 考果ザ者硫下 離尿ル人ルルル最射ノ著慮關ル二チ=

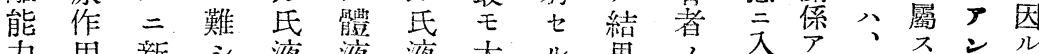

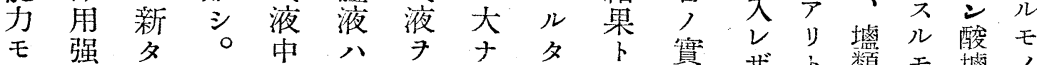

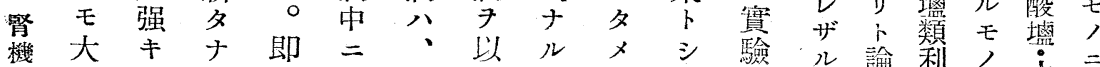
能二コル

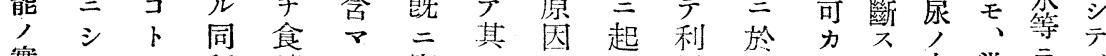

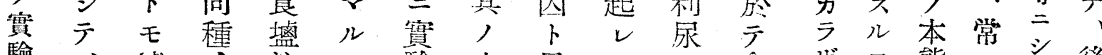

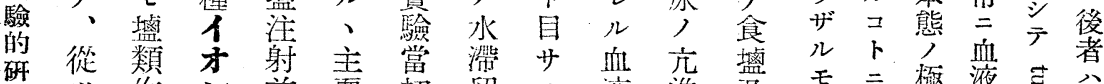

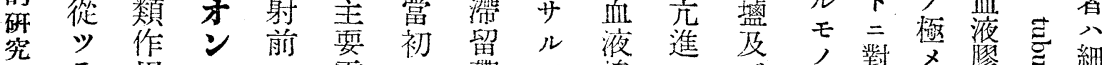

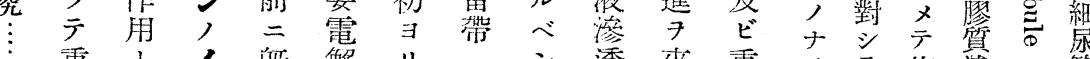

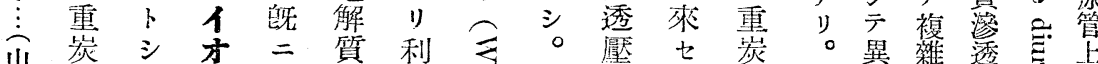

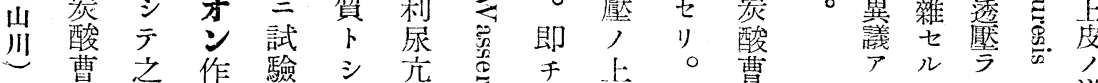

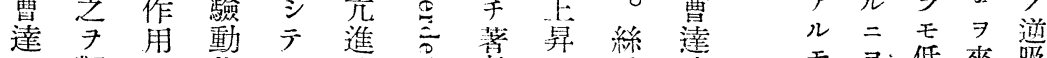

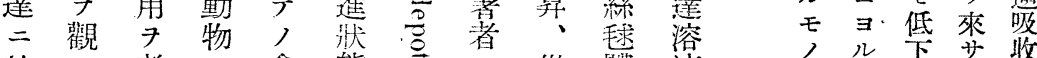

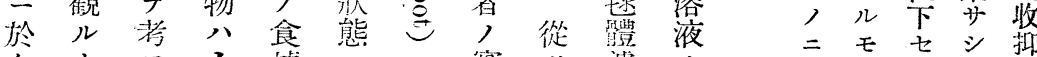

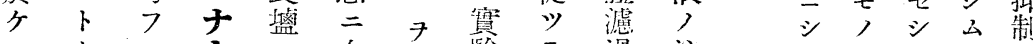

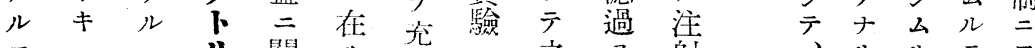

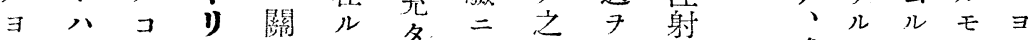
リ、卜方所少於三充少或べモ,

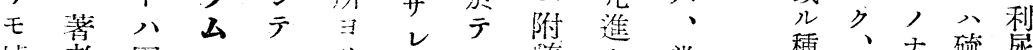
畦者困;

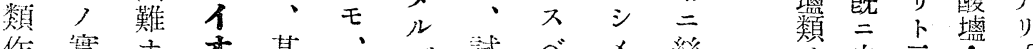

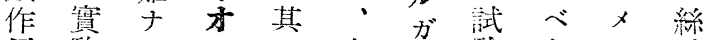

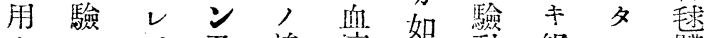
トニ ハ 及滲液如動組ル骨豊 シ於ナビ透二狀物織琶憈

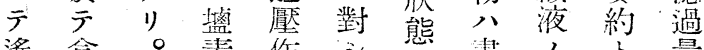

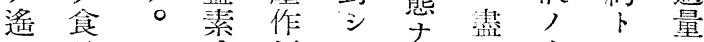

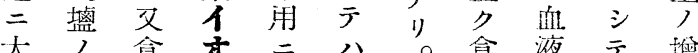
$ナ$ 試盖ン 加胳而盐闪少

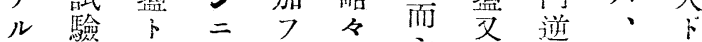
作例重依儿等紊少流食細 用二炭り 二沴テ重二坥尿

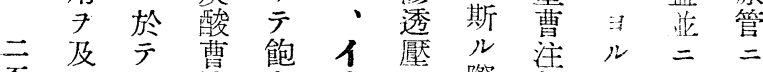

五ボ八達和䇄, 際射血重 於 ス注二, ン モ前液若々 モ射。於爿作, 組引; 酸儿 , 量 テ 態用夕織り水蹰逆 卜多 考 ク、在存 ベリ二离, 收

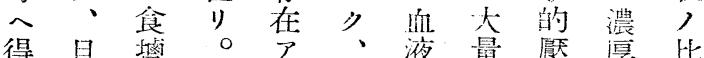

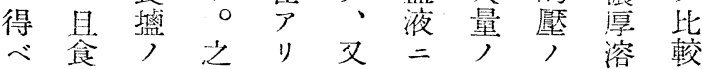
シ盐方二トリ逆り充液的 。正二抈八V 流 $ン$ 進 7 坜 投血云燐 氏 與 騦。酸 三類 前 毗 几度七酸 酸, 儿漗气 塭增如沃 基加》化采 䱛減類方物 少尿り息 之同機㕕 附同㭙㙨裹葿 隨 三 求起 万存關素 儿在入糖儿 他 ス 等 モ 八ル諸ナ， 漗悡家り。公 類尿 見食 變 $\exists$ 解 然臭

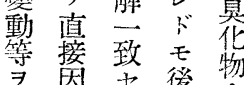




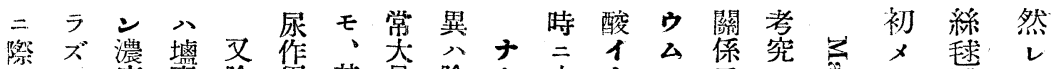

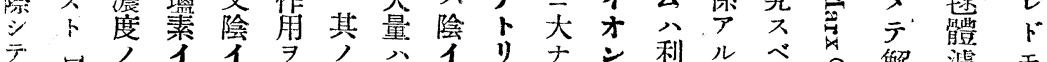

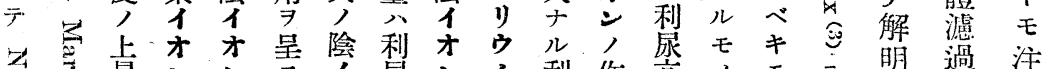

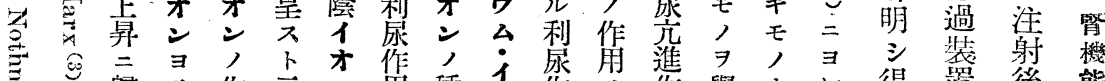

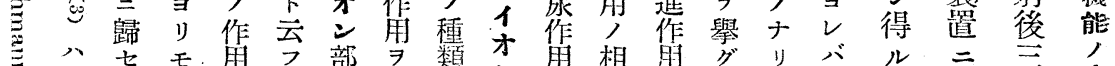
莺云り 小方

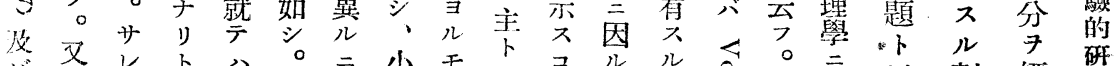

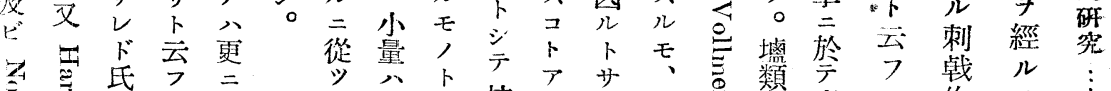

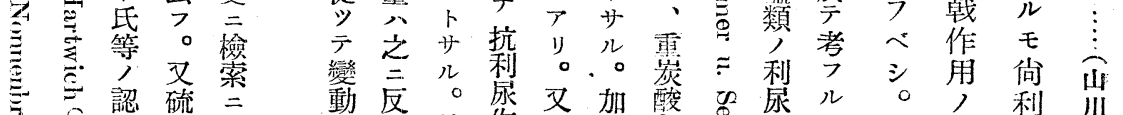

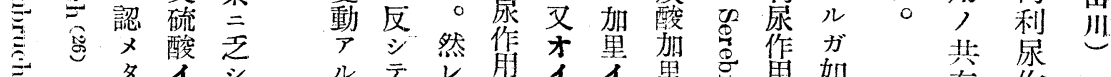

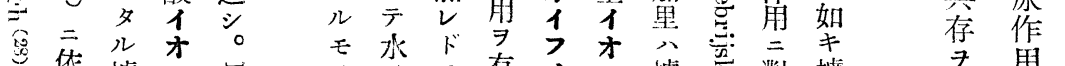

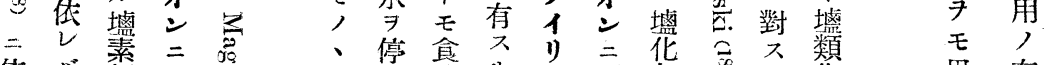

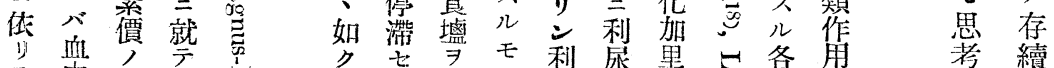

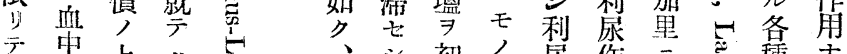

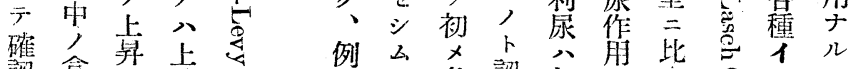

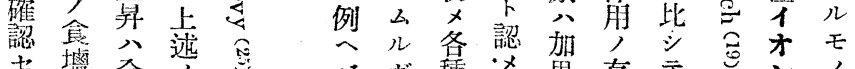

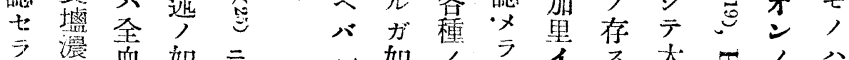

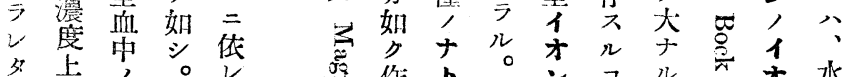

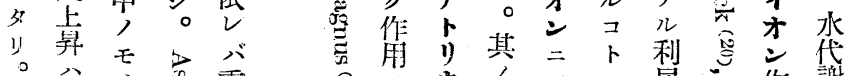

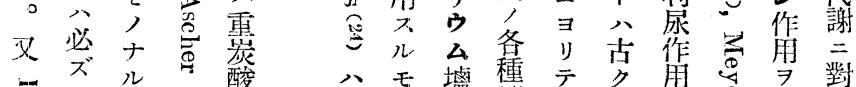

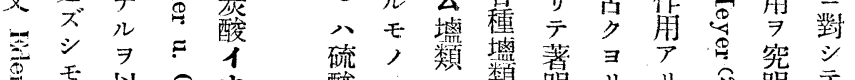

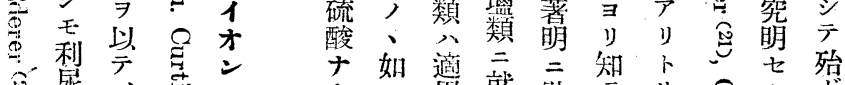

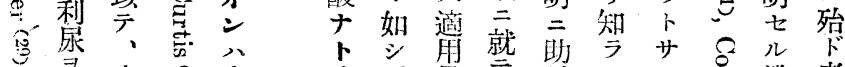

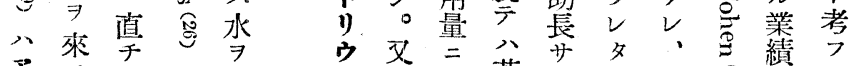

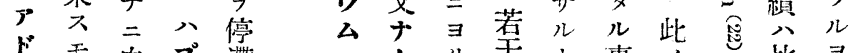

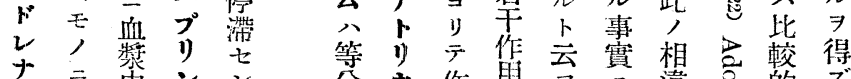

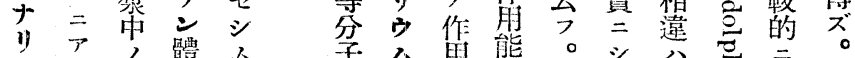

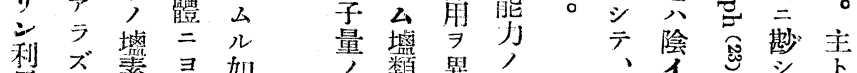

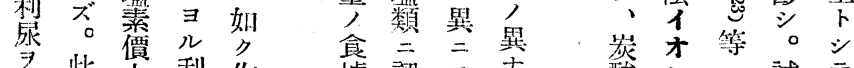

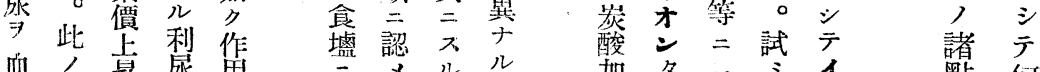

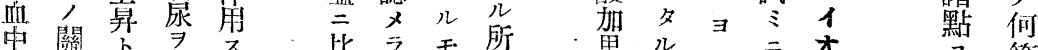

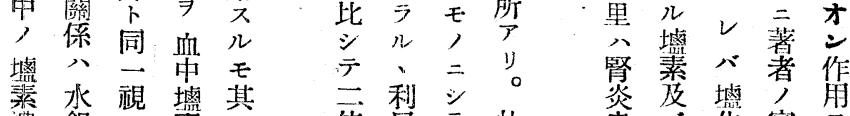

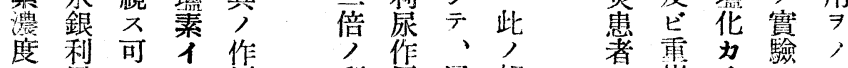

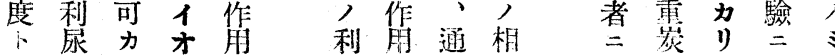

七 $七$

シ $ル$

台采

モ 斯

此篕

人類

閒 作

) 用

沿 二

息 加

堅ル

流 二

睡 才

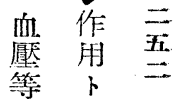
$\begin{array}{ll}7 & \text { 何 } \\ \text { 等 }\end{array}$

明 力

力 食

二 塭

シ 1 


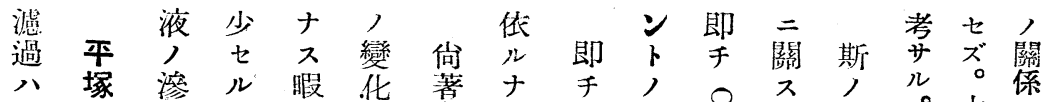

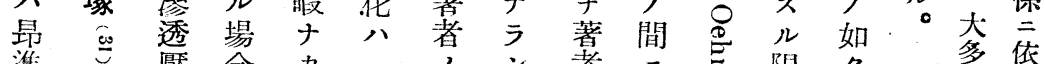

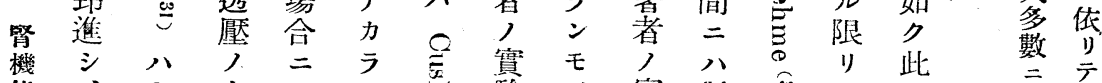

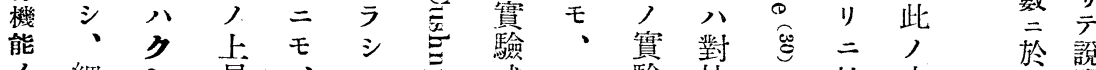

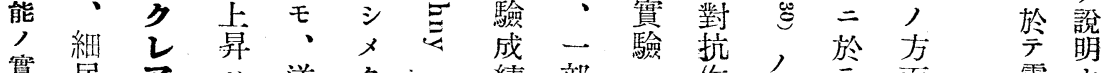
驗尿 的管于 逆吸儿說二八於用云八二解

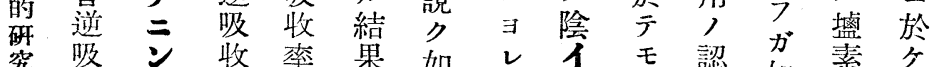

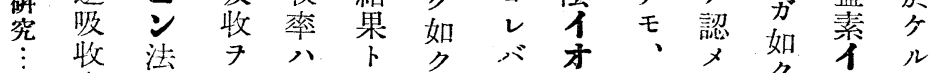

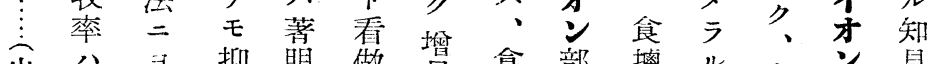

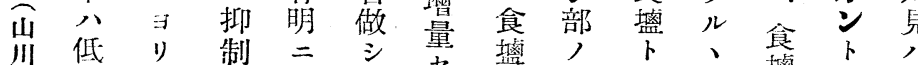

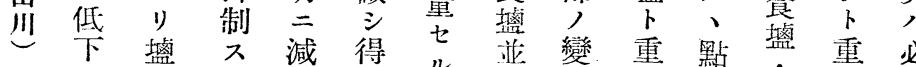
七類 ル少穴綵二花炭 $\exists$ 炭 リ利モ七キ綵重二酸り重酸

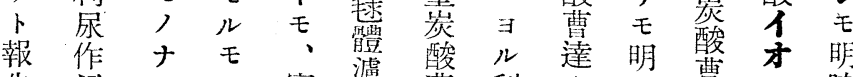
告用ル, 實濾笛利卜ナ蔳シ睹

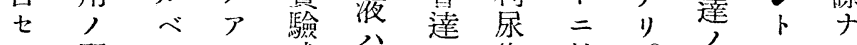
り腎シり成縕二作於。投二リ

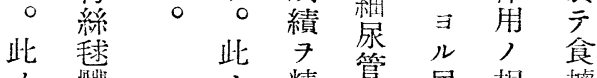

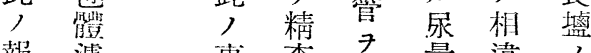
報 濾事 枯 7 量違,

告過䔈 ス急增 7 方 皇 $\quad$ ル 速加モ三

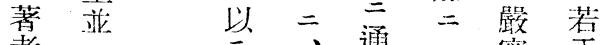

者

細

得 尿

タ 管

ル洋

成吸

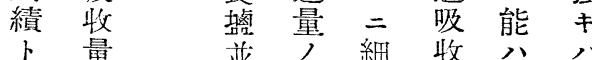

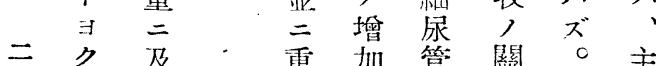

吾”文・重加管關。主

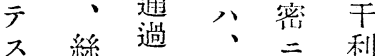

求三、細否尿

バ體尿定 作

、濾夕管正用 食過 $x$ 逆 ル强

至柰

ス 影

ル 響

所 7

ナ 檢

”。

酸 ズ皮

曹・

達 或 シ コ

$=八 \bar{r}$

$\exists$ 却 水 明

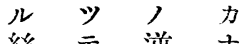

綵

絲宁逆 ナ

求

球多吸り

體少收。

主
三
璁
類
㤰
用
相
違

與於爷

摛可云

類 或 難

平》

衡, 王

對 才 蔁

兑者

㤰用檢

角 笙

七

1) 買

》, 範

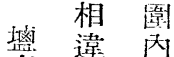

濃試

度

減》

溜。

7 經

認口

$x$ 的

居 水

儿投

毛與

主,

r 血

シ 中

$\overline{\text { 電 }}$

試蟹

殮 筫

期 變

動

個 =

體，就

榩

代

检

牀学

態

依多

光 $几$

素違內 種

ル食基

オ 盟變 知

人及憅見

卜 ビ乘必

重哂重岑 スズ

酸 三酸至

杂。遭息致 


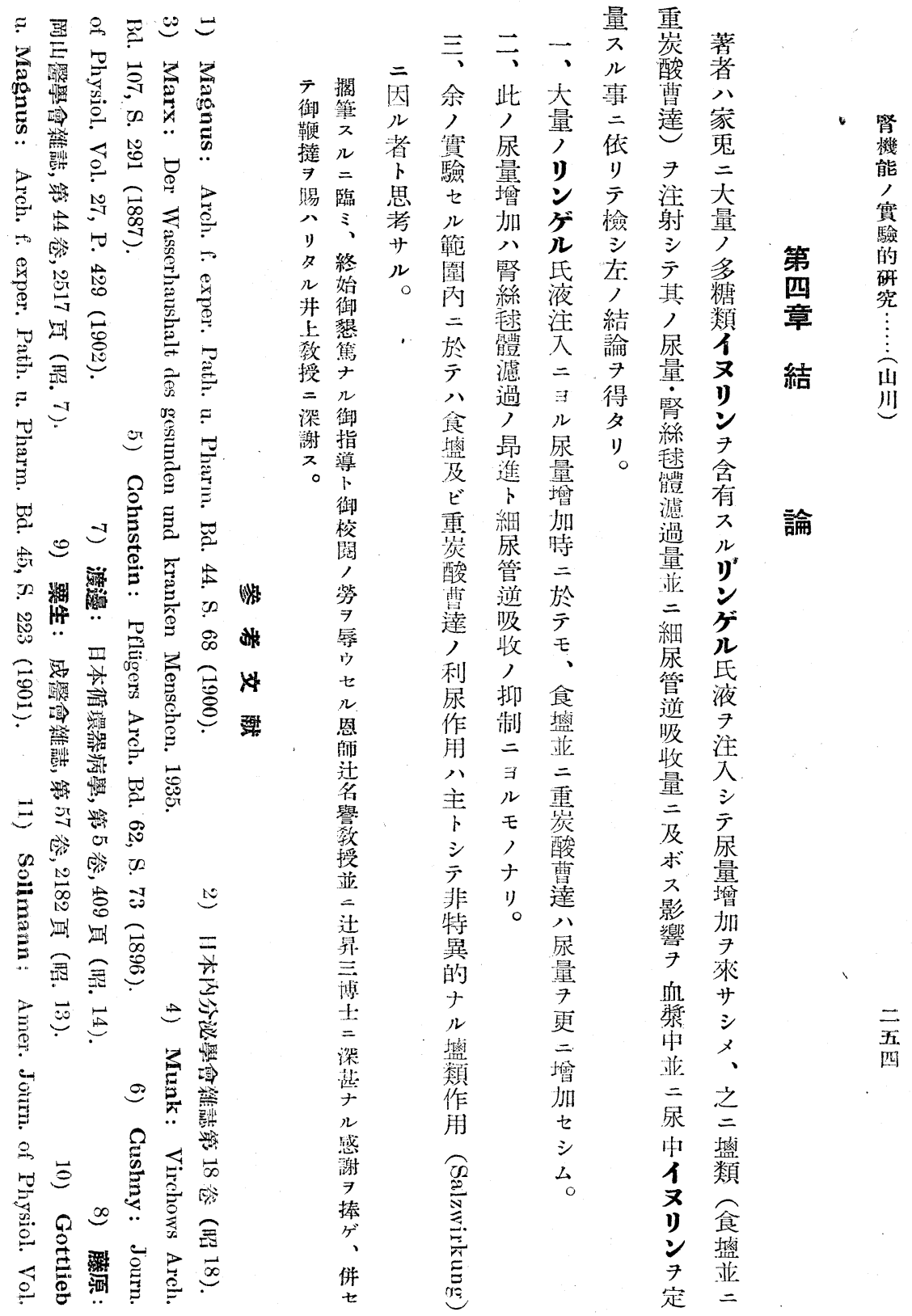


緊
機
能
實
驗
的
研
究
$\vdots$
$\vdots$
岗
川

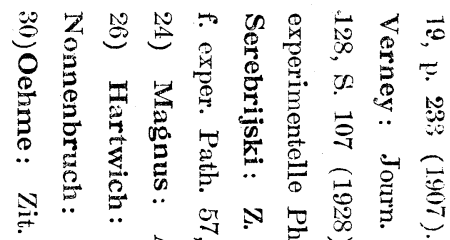

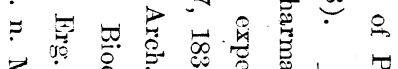

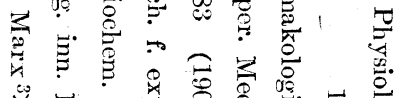

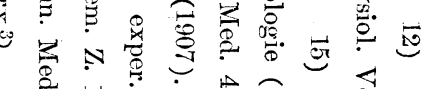

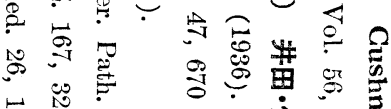

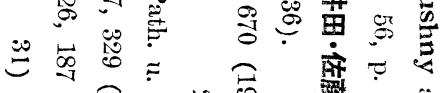

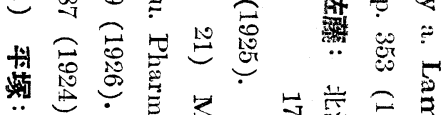

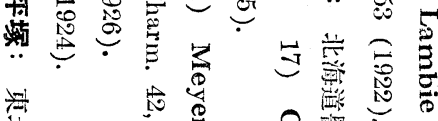

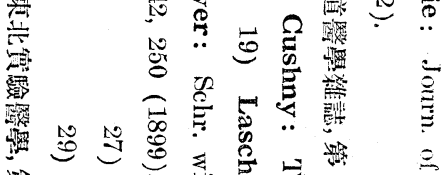

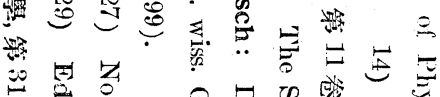

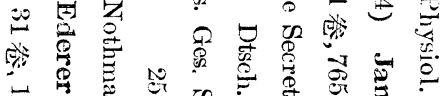

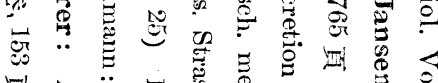

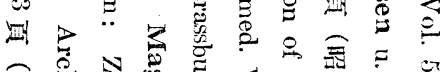
$\overrightarrow{0}$

吾

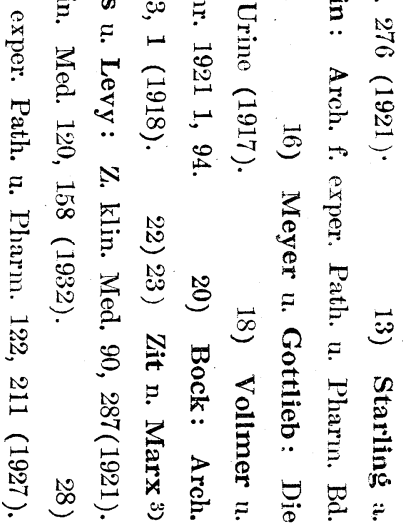


Harnmenge rapid kleiner, die Filtrationsmenge in den Glomeruli auch, und die Rückresorptionsmenge in den Harnkanälchen nimmt zu.

3) Selbst bei starker Diurese unter Zufuhr grosser Mengen Ringerscher Lösung vermögen die Harnkanälchen wenigstens $60 \%$ der in den Glomeruli filtrierten Wassermenge zurückzuresorbieren.

4) Die Harnmenge, Filtrationsmenge in der Glomeruli und die Rückresorptionsmenge in den Harnkanälchen zeigen grosse individuelle Verschiebungen. Aber im allgemeinen kann man wie folgt sagen : Die menge des Glomerulusfiltrates ist auch gross, wenn die Harnmenge gross ist. Zwischen Harnmenge und Rückresorptionsmenge kam kein bestimmtes Verhältnis nachgewiesen werden, aber der Rückresorptionskoeffizient $\left(\frac{\text { Rückresorptionsmenge }}{\text { Filtrationsmenge }} \times 100\right)$ wird gewöhnlich kleiner parallel mit der Zunahme der Harnmenge. Aus diesem Resultaten kann man folgern, dass die bei diesem Versuche beobachtete Diurese auf die Zunahme der Filtrationsmenge und weiter noch in grösserem Masse auf die relative Bremsung der Rückresorption in den Harnkanälchen zurückzufünren ist.

(Autoreferat)

\section{Experimentelle Studien über die Physiologie der Niere.}

III. Einfluss der Natriumsalze (Kochsalz und Natriumbicarbonat) auf die Filtrations- und Rückresorptionsverhältnisse in der Niere bei Zufuhr einer grossen Menge Flüssigkeit.

Von

Dr. U. Yamakawa.

(Aus der I. Med. Klinik der Kaiserl. Universität zu Kyoto in Japan.

Exvorstand: Prof. Emerit. K. Tsuji, Vorstand: K. Inoue)

Im Anschluss an seine 1. u. 2. Mitteilung hat der Verfasser versucht, über die Wirkungsweise der. Natriumsalze auf den Bil- 
dungsvorgang des Harns in der Niere Klarheit zu schaffen. Als Natriumsalze wurden Kochsalz und Natrium bicarbonicum gewählt. Als Versuchstiere dienten ausschliesslich gesunde ausgewachsene (ca. $2.0 \mathrm{~kg}$ schwere) Kaninchen. Nachdem die Tiere einige Tage lang mit Standardkost und einer bestimmten Wasserbeigabe ernährt wurden, wurden sie mit Urethan narkotisiert und in Rückenlage fixiert. Von der linken marginalen Vena aus wurde ihnén körperwarme Ringersche Lüsung, der in $15 \mathrm{mg} \%$ iger Konzentration Inulin zugesetzt war, dauernd infundiert. Dass $15 \mathrm{mg} \%$ Inulin, in Ringerscher Lösung zugesezt, keinen hemmenden Einfluss mehr anf die Diurese ausüben kann, wurde bereits in der 2. Mitteilung berichtet. Auf dem Bauch wurde in der Medianlinie ein kleiner Schnitt gemacht, aus welchem die Harnblase, zusammen mit dem Ureteransatz herausgeholt werden konnte. Am Ureteransatz wurde der Ureter eine ganz wenig gespaltet. Durch diese Spalte wird eine kleine Glas- oder Stahlnadel in den Ureter eingeführt.

Man wartet $a b$, bis die Tropfenzahl des Harns in gleichmässigem Tempo aus der Nadel herausfliesst. Zunächst wird die in 10 Minuten herausfliessende Harnmenge einerseits oder peiderseits (einoder zweimal) korrekt gemessen. Alsdann wird $10 \%$ ige Kochsalzlösung oder $5 \%$ ige Natriumbicarhonatlösung von der rechten marginalen Vena aus injiziert. Die Harnmenge wird in weiteren 10 Minuten fortlanfend gemessen. Vor der Salzinjektion und während des Vesuchs, gerade im Mittelpunkt jeder Ablesung der Harnmenge, wird aus der rechten Carotis 0.1-0.8 cem Blut zur Blutprobe entnommen. Der Inulingehalt der so gewonnenen Harnund Blutprobe wird nach der in der 1. Mitteilung beschriebenen Methode bestimmt.

Die Blutprobe wird bei jeder Entnahme stets durch Zusatz einer kleinen Menge Kalium oxalats vor dem Gerinnen geschützt. Die Filtrations- und Rückresorptionsmenge, bzw. die Harnmenge wurden wie gewöhnlich berechnet.

Aus dem Versuchsergebisse kann man wie folgt schliessen:

1) Selbst bei starker Diurese wie in diesem Versuche vermag 
der Zusatz des Kochsalzes oder Natrium biocarbonat die Diurese weiter zu steigern.

2) Die in diesem Versuche festgestellte diırese-fördernde Wirkung von Kochsalz oder Natrium bicarbonat beruht auf der Steigerung der Filtration in den Glomeruli einerseits und der Hemmung der Rückresorption in den Harnkanälchenandererseits.

3) Der Meinung des Verfassers nach ist die in diesem Versuch festgestellte diuretische Wirkung der beiden Natriumsalze eher als einfache Salzwirkung zu verstehen als eine spezifische Ionenwirkung.

(Autoreferat)

\title{
Experimentelle Studien über die Physiologie der Niere.
}

\section{V. Einfluss von Coffein, Theocin und Salyrgan auf den Bildungsmechanismus des Harns bei starker Wasserdiurese.}

\author{
Von \\ Dr. U. Yamakawa.
}

(Aus der I. Med. Klinik der Kaiserl. Universität zu Kyoto in Japan.

Exvorstand: Prof. Emerit. K. Tsuji, Vorstand: K. Inoue)

In diesem Versuchte versuche der Verfasser über den Wirkungswechanismus von Coffein, Theocin und Salyrgan auf die Filtrationsund Rückresorptionsverhältnisse in der Niere Klarheit zu schaffen. Die Versuchsbedingungen waren fast dieselben wie die in der 3. Mitteilung beschriebenen. Bei diesem Versuche wurde aber die Infusion der grossen Menge Ringersche Lösung (15-20 mg/dl Inulinhaltig) gerade vor der Entnahme der Harn- und Blutprobe unterbrochen. Nach der ersten Ablesung der Harnmenge wurde Coffein oder Theocin intravenös injiziert.

Beim Salyrganversuche gingen die Tiere sehr oft gleich nach der intravenösen Salyrganinjektion zugrunde, sodass der Versuch 